doi: 10.25005/2074-0581-2019-21-2-298-304

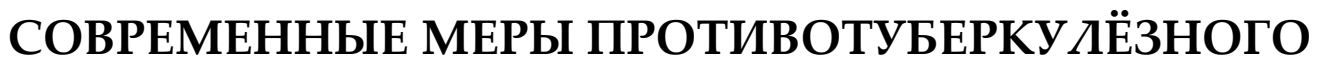 ИНФЕКЦИОННОГО КОНТРОЛЯ
}

\author{
О.И. БОБОХОДЖАЕВ ${ }^{1}$, 3.Т. АВГОНОВ ${ }^{2}$, С.С. САТТОРОВ 2
}

1 Кафедра фтизиопульмонологии, Таджикский государственный медицинский университет им. Абуали ибни Сино, Душанбе, Республика Таджикистан

2 Отдел науки, Научно-исследовательский институт профилактической медицины Таджикистана, Душанбе, Республика Таджикистан

\begin{abstract}
Для эффективного внедрения современных мер ликвидации туберкулёза (ТБ) необходимо располагать данными о факторах трансмиссии ТБ инфекции и его эпидемиологии, которые базируются на его патогенезе, начиная от инфицирования и до исходов его течения. Обзорная статья раскрывает современные требования и методы организации противотуберкулёзного инфекционного контроля. Представлены результаты публикаций, их интерпретация и сопоставление с ситуацией в Таджикистане. Показана важность соблюдения мер инфекционного контроля на дому, включая изоляцию бактериовыделителей, своевременную верификацию инфицированности микобактериями ТБ, вакцинацию и химиопрофилактику для улучшения эпидемиологической ситуации по ТБ. Отмечено, что доказательные принципы предотвращения нозокомиальной трансмиссии ТБ инфекции позволили сократить кратность госпитализаций и минимизировать сроки пребывания больных в ТБ стационарах, одновременно увеличив когорты больных, находящихся изначально на амбулаторной химиотерапии. Представленный обзор и реально существующий уровень противотуберкулёзного инфекционного контроля в Республике Таджикистан, в особенности в очагах инфекции и среди контактных лиц, свидетельствуют о необходимости принятия срочных мер по пересмотру подходов к профилактике трансмиссии этого грозного заболевания.

Ключевые слова: туберкулёз, инфекционный контроль, дезинфекция, микобактерии туберкулёза, иммунодиагностические методы, профилактика.
\end{abstract}

Для цитирования: Бобоходжаев ОИ, Авгонов ЗТ, Сатторов СС. Современные меры противотуберкулёзного инфекционного контроля. Вестник Авиценны. 2019;21(2):298-304. Available from: http://dx.doi.org/10.25005/2074-0581-2019-21-2-298-304.

\section{MODERN MEASURES OF ANTI-TB INFECTION CONTROL}

\section{O.I. BOBOKHODZHAEV ${ }^{1}$, Z.T. AVGONOV², S.S. SATTOROV ${ }^{2}$}

${ }^{1}$ Department of Physiopulmonology, Avicenna Tajik State Medical University, Dushanbe, Republic of Tajikistan

2 Department of Science, Scientific Research Institute of Preventive Medicine of Tajikistan, Dushanbe, Republic of Tajikistan

For effective implementation of modern TB eradication measures should be available to data on TB transmission factors and epidemiology based on it pathogenesis, from infection before the outcome of its current. Review article reveals the modern requirements and methods of organizing anti-TB infection control. The results of the publications, their interpretation and comparison with the situation in Tajikistan are presented. The importance of following infection control measures at home, including the isolation of bacterioexcretion persons, timely verification of mycobacterium TB infection, vaccination and chemoprophylaxis to improve the TB epidemiological situation. It is noted that the evidence-based principles of preventing nosocomial transmission of TB infection have reduced the number of hospitalizations and minimized the duration of patients' stay in TB hospitals, while increasing the cohorts of patients who are initially on outpatient chemotherapy. The review presented and the real level of anti-TB infection control in the Republic of Tajikistan, especially in the nidus of infection and among contact persons, indicates the urgent need to rethink approaches to preventing transmission of this disease.

Keywords: Tuberculosis, infection control, disinfection, mycobacteria tuberculosis, immuno-diagnostic methods, prevention.

For citation: Bobokhodzhaev OI, Avgonov ZT, Sattorov SS. Sovremennye mery protivotuberkulyoznogo infektsionnogo kontrolya [Modern measures of antiTB infection control]. Vestnik Avitsenny [Avicenna Bulletin]. 2019;21(2):298-304. Available from: http://dx.doi.org/10.25005/2074-0581-2019-21-2-298-304.

$\Gamma$ ля эффективного внедрения современных мер ликвидации туберкулёза (ТБ) необходимо располагать данными о факторах трансмиссии ТБ инфекции и его эпидемиологии, которые базируются на его патогенезе, начиная от инфицирования и до исходов его течения [1]. Известно, что источником М. tuberculosis является больной бактериовыделитель. Источниками распространения ТБ в обществе являются больные активной формой ТБ, не находящиеся на лечении. Больные ТБ, которые получают адекватное лечение, в течение 2-4 недель уже не опасны для общества. Поэтому, основным мероприятием по предотвращению риска трансмиссии ТБ инфекции в обществе является быстрое выявление заразных и их адекватное лечение [1].

B.А. Аксёновой и соавт. установлено, что первостепенная роль в развитии множественной лекарственно-устойчивой (МЛУ) микобактерии ТБ (МБТ) у ребёнка принадлежит очагу с проживанием больного, выделяющего устойчивые к действию противотуберкулёзных препаратов (ПтП) штаммы M. tuberculosis, поскольку более половины детей с МЛУ МБТ имели в анамнезе контакт с больным с установленной МЛУ возбудителя [2]. Если принять во внимание высокую летальность, недостаточную эффективность, длительность и чрезвычайно высокую стоимость лечения этих форм заболевания (20-24 мес., до 20 тыс. долларов США на курс лечения), то становится вполне очевидным, что как с точки зрения эпидемиологии и общественного здоровья, так и с экономических позиций необходимо максимальное внедрение системы мероприятий противотуберкулёзного инфекционного контроля, основанной на международно-признанных доказательных принципах [3]. 
Важно внедрить в практику здравоохранения инновационные подходы, которые способствуют работать по-другому и разорвать цикл передачи инфекции [4]. Необходим мультидисциплинарный подход к решению проблем. Важной составляющей дальнейшего улучшения профилактики и лечения ТБ является интегрированный подход систем здравоохранения ${ }^{1}$.

Доказательные принципы предотвращения нозокомиальной трансмиссии ТБ инфекции позволили сократить кратность госпитализаций и минимизировать сроки пребывания больных в ТБ стационарах, одновременно увеличив когорты больных, находящихся изначально на амбулаторной химиотерапии. Поэтому основными путями распространения ТБ инфекции в обществе являются больные, которые только начали приём ПтП в условиях ПМСП и пока ещё являются бактериовыделителями. Поэтому решение о лечении бактериовыделителя в домашних условиях должно приниматься, в том числе с учётом возможности всех условий инфекционного контроля².

После начала эффективного режима химиотерапии бактериологическая нагрузка быстро снижается, и в течение нескольких дней пациент перестаёт быть контагиозным³. По данным исследований, проведённых Dharmadhikari AS et al (2014), даже больной ТБ с МЛУ МБТ перестаёт быть контагиозным на фоне лечения [5].

Кроме того, поскольку для передачи ТБ кратковременный контакт с больным недостаточен, поэтому не находящиеся в программе больные в основном имеют высокий риск трансмиссии ТБ инфекции в основном среди тех, с кем проживают или находятся в длительном контакте ${ }^{4}$.

В основном, контакт с больными активным ТБ в семейных очагах, как правило, длится на протяжении нескольких месяцев до постановки диагноза, восприимчивые люди из числа находившихся в контакте с больным уже инфицированы, исключая тем самым необходимость изоляции от них пациента даже на те 14 дней, в течение которых рекомендуется соблюдать осторожность в отношении контактов в целом [6].

Интенсивный рост заболеваемости МлУ ТБ на современном этапе определяется несовершенством подходов к эпидемиологическому надзору в изменившихся условиях развития эпидемического процесса, связанных с конкретными социально-экономическими преобразованиями и уровнем жизни [7].

Специальных мер по работе с контактными лицами необходимо придерживаться в городских условиях, где ТБ очаг распространяется на домохозяйства, соратников по работе или одноклассников, родственников, в общественном транспорте и пр. В этой связи, круг вероятных групп риска достигает 30-50 человек за сутки, хотя ранее на одного больного с активной формой ТБ было принято выявлять 3-4 контактных лиц. Как правило, контакты между жителями в сельской местности более тесные, социальные условия и доступ к медицинским услугам хуже, плохо развита транспортная система [8]. В то же время, по нашему мнению, при принятии решения об амбулаторном лечении следует учитывать особенности создания домохозяйств и ментали-

1 Godinho J, Veen J, Cercone J, Pacheco J, Dara M. Stopping tuberculosis in Central Asia: priorities for action. World Bank. accessed March 10, 2019.

2 Национальное руководство по инфекционному контролю за туберкулёзом в Республике Таджикистан. Душанбе. 2013. 42 с.

3 Tuberculosis: prevention, diagnosis, management and service organization. London: National Institute for Health and Care Excellence. 2016. 84

4 Амбулаторная помощь и контагиозность туберкулёза. Copenhagen: WHO Regional Office for Europe. 2018. 5. тет народов Средней Азии, в особенности в нашей стране, где в одном домохозяйстве проживают несколько семей (родители и дети со своими семьями). Это не соответствует известным стандартам по охвату профилактическими мерами контактных лиц и имеет сложности изолирования пациента на дому, в связи с традициями посещений его родственниками [9].

При организации мер по предотвращению трансмиссии МБТ следует учитывать, что иммуноскомпроментированные лица (ВИЧ инфицированные, онкологические больные на фоне иммунодепрессантов и др.) в отличие от иммуносохранённых лиц, более подвержены реактивации туберкулёзного процесса, равно как и факт, что абацилирование у первых наступает в более поздние сроки химиотерапии [10].

Эпидемиологическая опасность туберкулёзной инфекции выражается также и высокой степенью инфицированности детей МБТ. Особенно высокие показатели инфицированности и заболеваемости ТБ выявлены у детей из очагов ТБ, которые превышают общий показатель в 2,5 раза, что подтверждает значимость туберкулёзного контакта в сохранении напряжённой ситуации по ТБ среди детского населения. Заболеваемость детей в очагах ТБ инфекции более чем в 30 раз, а подростков в 25 раз выше этих же возрастов вне очага [2].

В качестве примера приведём данные об уровне инфицированности МБТ у детей в г. Санкт-Петербург, который составил $25 \%$, а в очагах ТБ достиг $60 \%$, а заболеваемость детей в очагах ТБ инфекции в 13 раз больше, чем среди всего детского населения (228,6 на 100 тыс. контактных и 17,4 на 100 тыс. детей, соответственно) [11]. В то же время нам видится не вполне корректным сравнивать показатель заболеваемости на 100 тысяч контактных детей с 100 тысячами от общего числа детей. Ряд исследователей установил сильную прямую корреляционную зависимость между присоединением в будущем у ребёнка туберкулёзной инфекции и плохими жилищно-бытовыми условиями [12, 13]. По результатам многочисленных исследований можно обобщить, что основными направлениями совершенствования ПМСП контактным детям являются: сохранение основных структур противотуберкулёзной службы (ПтС) на районном уровне, совместная работа ПМСП, СЭС и районной ПТС по профилактике и раннему выявлению ТБ у детей; совершенствование системы выявления первичного инфицирования и заболевания ТБ у детей из очагов ТБ, с учётом факторов риска, влияющих на развитие у ребёнка туберкулёзной инфекции; внедрение норм и правил инфекционного контроля в стационарах и стационаро-замещающих учреждениях [14-16].

Уровень инфицированности определяет объём резервуара ТБ инфекции, и она характеризует эпидемиологическое бремя заболеваемости, хотя снижение показателя заболеваемости часто происходит раньше снижения распространённости инфицированности. Общеизвестно, что один бактериовыделитель является источником трансмиссии ТБ инфекции у 10-15 человек в течение года.

В литературе широко дискутируются разные методы выявления туберкулёзной инфекции. Иммунодиагностика включает верификацию инфицированности МБТ и проводится массово или индивидуально. Первый или скрининговый подход проводится со стороны специалистов ПМСП [17].

Овсянкина ЕС и соавт. для иммунодиагностики инфицированности МБТ изучили сравнительную информативность пробы Манту и пробы с туберкулёзным рекомбинантным аллергеном (диаскинтест) и рекомендовали для скрининга использовать туберкулиновую пробу [18]. В то же время Слогоцкая ЛВ и соавт., 
проведя подобные наблюдения, делают заключение, что низкая специфичность туберкулинодиагностики среди детей после первичной специфической профилактики и частота положительных реакций обусловлена в основном поствакцинальной аллергией, что исключается при использовании диаскинтеста [19]. Этого же мнения придерживаются и многие другие исследователи данной проблемы [20-23]. Появление новых иммунных тестов (IGRA) существенно изменило ситуацию в определении туберкулёзной инфекции без повышения риска развития ТБ [24-26].

Одной из основных целей реализации мероприятий по профилактике и лечению ТБ является повышение их ориентированности на потребности людей, что означает дальнейшее развитие и совершенствование моделей амбулаторно-поликлинической и стационарной специализированной помощи ${ }^{5}$.

Инфекционный контроль внутрибольничной микобактериальной инфекции в ПтС играет важную роль в ограничении распространения ТБ в обществе $[27,28]$. Опубликовано много сведений о нозокомиальной трансмиссии ТБ, включая руководства ВО3 $[29,30]$. Имеются также фактические данные о том, что госпитализация является серьёзным фактором риска передачи МЛУ ТБ и ШЛУ ТБ среди больных ТБ [31-33]. В связи с этим, госпитализация рекомендуется, как правило, только при развитии осложнений или при наличии у пациента сопутствующих медицинских проблем ${ }^{6}$.

Превентивные меры позволяют снизить трансмиссию ТБ инфекции и включают первичную (вакцинация) и вторичную (химиопрофилактика) профилактику, а также санитарную и социальную профилактику, и инфекционный контроль [34].

Первичная профилактика вакцинацией БЦЖ и вторичная или химиопрофилактика описаны ранее достаточно хорошо. Цель санитарной профилактики - предотвратить трансмиссию ТБ инфекции в обществе, максимально обезопасить контакт с бактериовыделителем дома и вне его, а также проведение социальных и противоэпидемических мер в месте постоянного пребывания больного. В основе социальной профилактики лежит внедрение мер профилактики со стороны государства, предоставление социальных гарантий и доступных бесплатных услуг ${ }^{7}$.

Противотуберкулёзный инфекционный контроль - это комплекс мер по предотвращению трансмиссии M. tuberculosis и инфицирования здоровых или реактивации ТБ процесса у переболевших ТБ лиц посредством реинфекции (суперинфекции). Эта цель достигается путём:

- у управленческих мер по установлению ответственных лиц и разработки реального плана инфекционного контроля;

- административных мер по минимизации пребывания бактериовыделителя в учреждениях ПТС, сортировки и изоляции их до конверсии мокроты;

- $\quad$ мер, связанных с улучшением качества воздуха путём внедрения эффективных мероприятий по вентиляции и его ультрафиолетовому облучению, и др.;

- мер индивидуальной защиты - обучение гигиене кашля и использованию медицинской маски, а также

5 Guiding principles to reduce tuberculosis transmission in the WHO European Region. Copenhagen: WHO Regional Office for Europe; 2018. 26 p.

6 Методические рекомендации по применению метода аэрозольной дезиндекции в медицинских организациях. Утв. Роспотребнадзором 28.09.2015. Москва. 18 с.

7 Методические рекомендации «Порядок работы с аэрозолями микроорганизмов с иелью проверки бактерицидной эффективности дезинфицирующих средств. Утв. ФБУН ГНЦ ПМБ 21.05.2014. Москва. 22 c. использованию респираторов специальных серий медицинскими работниками ${ }^{8}$.

Под очагом ТБ инфекции подразумевают постоянное место пребывания больного с активной формой ТБ и соответственно сообщество, с которым он тесно связан. Оздоровление очага ТБ инфекции - это комплекс мер, направленных на профилактику трансмиссии ТБ инфекции среди членов близких с бактериовыделителем лиц [35].

Этот комплекс включает изолирование бактериовыделителя от детей в особенности и от других членов семьи; наблюдение за лицами, бывшими в контакте с больным, мониторинг проведения вакцинации БЦЖ новорождённых и изоляция их на период иммунного ответа; специфическая химиопрофилактика неинфицированных (подлежащих групп) и инфицированных возбудителем ТБ лиц [36]. Химиопрофилактика направлена на повышение резистентности организма к M. tuberculosis. Многие исследователи, одной из самых эффективных мер профилактики распространения ТБ инфекции считают раннее выявление латентного ТБ и охват химиопрофилактикой [37].

Немаловажное значение в комплексе мер профилактики ТБ необходимо уделять санитарно-гигиеническому воспитанию населения, улучшению условий быта и труда, быстрой верификации болезни и эффективной её химиотерапии на всех этапах лечения [1]. Большую эффективность для профилактики ТБ имеют мероприятия по профилактическому флюорографическому скринингу населения, который позволяет своевременно заподозрить, верифицировать и быстро начать адекватную химиотерапию.

В очагах ТБ инфекции положено дважды проводить дезинфекцию. Текущую дезинфекцию следует проводить сразу после экстренного оповещения о выявленном случае. Заключительную дезинфекцию следует проводить сразу после госпитализации больного или смены по разным причинам места проживания.

Внедрение современных мероприятий по дезинфекции и надежного контроля для предотвращения распространения МБТ в местах продолжительного компактного пребывания людей является важным компонентом управления ТБ программой. В Российской Федерации, в соответствии с приказом МЗ РФ от 15.11.2012 г. № 932н, предусмотрено оснащение птУ аппаратами, обладающими возможностью обеззараживания воздуха. Дезинфицирующее действие аэрозолей связано с испарением микрокапелек дезинфектанта и оседании неиспарившихся частиц на поверхности. Широко используемые на практике генераторы аэрозоля обогащают воздух зданий высокодисперсным (1-100 мкм) аэрозолем дезинфектанта, который контактирует непосредственно с парящими в воздухе микрочастицами и всеми поверхностями в помещении, одновременно равномерно обеззараживая их [37]. В доступной нам литературе описано множество методов лабораторных исследований и испытаний дезинфекционных средств, однако данные по их эффективности и безопасности разнятся. Текущая дезинфекция на дому включает: обеззараживание мест выплёвывания мокроты, туалета и белья, влажную уборку всех комнат в течение всего времени пребывания больного дома [37].

Таким образом, представленный обзор опубликованных исследований по рекомендованным современным мерам про-

8 Дезинфектология. Методы лабораторных исследований и испытаний дезинфекционных средств для оценки их эффективности и безопасности. Руководство. Утв. Роспотребнадзором 01.06.2010. Москва. $42 c$. 
филактики ТБ, с одной стороны, и реально существующий уровень противотуберкулёзного инфекционного контроля в Республике Таджикистан, в особенности в очагах инфекции и среди контактных лиц, а также результаты исследований по нараста- нию трансформации чувствительных форм ТБ в МЛУ ТБ, с другой, свидетельствуют о необходимости принятия срочных мер по пересмотру подходов к профилактике трансмиссии этого грозного заболевания.

\section{ЛИтеPATYPA REFERENCES}

1. Алексеенко СН, Дробот ЕВ. Профилактика заболеваний. Туберкулёз: эпидемиология, факторы риска, профилактика. Москва, РФ: «Российская Академия естествознания»; 2015. 449 с.

2. Аксёнова ВА, Клевно НИ, Кавтарашвили СМ, Казаков АВ, Пахлавонова АД. Очаг туберкулёзной инфекции как риск развития у детей туберкулёза с множественной лекарственной устойчивостью. Туберкулёз и болезни лёгких. 2018;96(1):11-7.

3. Покровский ВИ, Брико НИ. (ред.) Общая эпидемиология с основами доказательной медицины. Учебное пособие. Второе издание. Москва, РФ: ГЭОТАР-Медиа; 2012. 494 с.

4. Dara M. TB in Central Asia. WHO Regional Office for Europe. Panorama: Public Health. 2016;2(1):10-4.

5. Dharmadhikari AS, Mphahlele M, Venter K, Stoltz A, Mathebula R, Masotla T. et al. Rapid impact of effective treatment on transmission of multidrugresistant tuberculosis. Int J Tuberc Lung Dis. 2014;18(9):1019-25.

6. Ощепкова НМ, Винокурова МК. Особенности очагов туберкулёза в сельской местности в условиях региона Крайнего Севера. Якутский медицинский журнал. 2013;1(41):85-7.

7. Винокурова МК, Александров ВЛ, Яковлева ЛП, Ощепкова НМ. Тенденции развития эпидемиологической ситуации по туберкулёзу в Республике Саха (Якутия) в 2004-2011 гг. Якутский медицинский журнал. 2013;1(41):58-62.

8. Алиев СП, Бобоходжаев ОИ, Махмудзода ИС, Мирзоева ФО, Укуматшоева ЛШ, Мирзоева СР. Эффективность выявления случаев туберкулёза среди населения г. Душанбе Республики Таджикистан. Вестник Авиценны. 2018;20(4):427-30. Available from: http://dx.doi. org/10.25005/2074-0581-2018-20-4-427-430.

9. Сироджидинова УЮ, Бобоходжаев ОИ, Пиров КИ, Сироджидинов ФС. Выявляемость локального туберкулёза у школьников в разных регионах Республики Таджикистан. Вестник Авиценны. 2017;19(1):90-3. Available from: http://dx.doi.org/10.25005/2074-0581-2017-19-1-90-93.

10. Шилова МВ. Совершенствование диспансерного наблюдения контингентов противотуберкулёзных учреждений на основе персонального мониторинга пациентов с применением компьютерных технологий. Туберкулёз и болезни лёгких. 2014;7:8-15

11. Мордык АВ, Турина АА, Кондря АВ, Ароян АР, Цыганкова ЕА. Выявление различных форм и локализаций туберкулёза у детей разного возраста: роль скринингового обследования. Российский педиатрический журнал. 2016;19(3):151-6.

12. Бармина НА, Барышникова ЛА, Шурыгин АА, Рейхардт ВВ. Скрининг латентной туберкулёзной инфекции с применением аллергена туберкулёзного рекомбинантного. Туберкулёз и болезни лёгких. 2016;94(5):56-60.

13. Слогоцкая ЛВ, Богородская ЕМ. Сравнительная характеристика иммунологических тестов для выявления туберкулёзной инфекции. Возможность массового скрининга. Туберкулёз и болезни лёгких. 2016;94(5):5-17.

14. Кисличкин НН, Фурс СМ, Красильников НВ. Диагностика туберкулёза. Туберкулин или диаскинтест - что выбрать? Эпидемиология и инфекционные болезни. 2014;5:50-5.

1. Alekseenko SN, Drobot EV. Profilaktika zabolevaniy. Tuberkulyoz: epidemiologiya, faktory riska, profilaktika [Disease prevention. Tuberculosis: epidemiology, risk factors, prevention]. Moscow, RF: "Rossiyskaya Akademiya estestvoznaniya"; 2015. 449 p.

2. Aksyonova VA, Klevno NI, Kavtarashvili SM, Kazakov AV, Pakhlavonova AD. Ochag tuberkulyoznoy infektsii kak risk razvitiya u detey tuberkulyoza mnozhestvennoy lekarstvennoy ustoychivost'yu [Outbreak of tuberculosis infection as a risk of developing multidrug-resistant tuberculosis in children]. Tuberkulyoz i bolezni lyogkikh. 2018;96(1):11-7.

3. Pokrovskiy VI, Briko NI. (red.) Obshchaya epidemiologiya s osnovami dokazatel'noy meditsiny [General epidemiology with the basics of evidencebased medicine]. Vtoroe izdanie. Moscow, RF: GEOTAR-Media; 2012. 494 p.

4. Dara M. TB in Central Asia. WHO Regional Office for Europe. Panorama: Public Health. 2016;2(1):10-4.

5. Dharmadhikari AS, Mphahlele M, Venter K, Stoltz A, Mathebula R, Masotla T. et al. Rapid impact of effective treatment on transmission of multidrugresistant tuberculosis. Int J Tuberc Lung Dis. 2014;18(9):1019-25.

6. Oshchepkova NM, Vinokurova MK. Osobennosti ochagov tuberkulyoza v sel'skoy mestnosti $v$ usloviyakh regiona Kraynego Severa [Features foci of tuberculosis in rural areas in the conditions of the Far North region]. Yakutskiy meditsinskiy zhurnal. 2013;1(41):85-7.

7. Vinokurova MK, Aleksandrov VL, Yakovleva LP, Oshchepkova NM. Tendentsii razvitiya epidemiologicheskoy situatsii po tuberkulyozu v Respublike Sakha (Yakutiya) v 2004-2011 gg. [Trends in the epidemiological situation of tuberculosis in the Republic of Sakha (Yakutia) in 2004-2011]. Yakutskiy meditsinskiy zhurnal. 2013;1(41):58-62.

8. Aliev SP, Bobokhodzhaev OI, Makhmudzoda IS, Mirzoeva FO, Ukumatshoeva LSh, Mirzoeva SR. Effektivnost' vyyavleniya sluchaev tuberkulyoza sredi naseleniya g. Dushanbe Respubliki Tadzhikistan [Efficacy of tuberculosis cases detection among the population of Dushanbe in the Republic of Tajikistan]. Vestnik Avitsenny [Avicenna Bulletin]. 2018;20(4):427-30. Available from: http://dx.doi.org/10.25005/2074-0581-2018-20-4-427-430.

9. Sirodzhidinova UYu, Bobokhodzhaev OI, Pirov KI. Vyyavlyaemost' lokal'nogo tuberkulyoza u shkol'nikov v raznykh regionakh Respubliki Tadzhikistan [Detectability of pulmonary tuberculosis in schoolchildren from different regions of the Republic of Tajikistan]. Vestnik Avitsenny [Avicenna Bulletin]. 2017;19(1):90-3. Available from: http://dx.doi.org/10.25005/2074-05812017-19-1-90-93.

10. Shilova MV. Sovershenstvovanie dispansernogo nablyudeniya kontingentov protivotuberkulyoznykh uchrezhdeniy na osnove personal'nogo monitoringa patsientov s primeneniem komp'yuternykh tekhnologiy [Improvement of follow-up monitoring of contingents of tuberculosis institutions based on personal patient monitoring using computer technologies]. Tuberkulyoz $i$ bolezni lyogkikh. 2014;7:8-15.

11. Mordyk AV, Turina AA, Kondrya AV, Aroyan AR, Tsygankova EA. Vyyavlenie razlichnykh form i lokalizatsiy tuberkulyoza u detey raznogo vozrasta: rol' skriningovogo obsledovaniya [Identification of various forms and localizations of tuberculosis in children of different ages: the role of screening tests]. Rossiyskiy pediatricheskiy zhurnal. 2016;19(3):151-6.

12. Barmina NA, Baryshnikova LA, Shurygin AA, Reykhardt VV. Skrining latentnoy tuberkulyoznoy infektsii $S$ primeneniem allergena tuberkulyoznogo rekombinantnogo [Screening for latent tuberculosis infection using a recombinant tuberculosis allergen]. Tuberkulyoz $i$ bolezni lyogkikh. 2016;94(5):56-60.

13. Slogotskaya LV, Bogorodskaya EM. Sravnitel'naya kharakteristika immunologicheskikh testov dlya vyyavleniya tuberkulyoznoy infektsii. Vozmozhnost' massovogo skrininga [Comparative characteristics of immunological tests for the detection of tuberculosis infection]. Tuberkulyoz i bolezni lyogkikh. 2016;94(5):5-17.

14. Kislichkin NN, Furs SM, Krasilnikov NV. Diagnostika tuberkulyoza. Tuberkulin ili diaskintest - chto vybrat'? [Diagnosis of tuberculosis. Tuberculin or diaskintest - what to choose?]. Epidemiologiya i infektsionnye bolezni. 2014;5:50-5. 
15. Поддубная ЛИ, Шилова ЕП, Степченко ИМ. Эпидемиологические факторы и иммунные пробы в формировании групп риска по заболеванию туберкулёзом. Туберкулёз. 2015;5:153-4.

16. Возякова ТР, Мастерова АВ, Еленкина ЖВ, Кудлай ДА. Комплексная оценка диагностических методов выявления туберкулёзной инфекции у детей и подростков в Чувашской Республике. Российский вестник перинатологии и педиатрии. 2017;62(4):105-12.

17. Аксёнова ВА, Барышникова ЛА, Клевно НИ. Новые возможности скрининга и диагностики различных проявлений туберкулёзной инфекции у детей и подростков в России. В: Пальцев МА. (ред.) Кожная проба с препаратом "Диаскинтест» - новые возможности идентификации туберкулёзной инфекции. Изд. 2-е. Москва, РФ: ЗАО «Мастерклон»; 2011. с. 134-52.

18. Овсянкина ЕС, Губкина МФ, Панова ЛВ, Юхименко НВ. К вопросу о влиянии методы скрининга туберкулёзной инфекции у детей и подростков на формирование групп риска и диагностику заболевания. Педиатрическая фармакология. 2016;13(6):617.

19. Слогоцкая Л, Богородская ЕМ, Сенчихина ОЮ, Никитина ГВ, Кудлай ДА. Формирование групп риска заболевания туберкулёзом при различных иммунологических методах обследования детского населения. Российский педиатрический журнал. 2017;20(4):204-13.

20. Поддубная ЛВ, Шилова ЕП, Степченко ИМ, Кононенко ВГ. Эпидемиологические факторы и иммунологические пробы в формировании групп риска по заболеванию туберкулёзом. Туберкулёз и болезни лёгких. 2015;5:153-4.

21. Aggerbeck $H$, Giemza R, Joshi P. Randomised Clinical trial investigating the specificity of a Novel skin test (C-TB) for diagnosis of M. Tuberculosis infection. PloS ONE. 2013;8(5):e64215.

22. Legesse M, Ameni G, Mamo G. Community-based cross-sectional survey of latent tuberculosis infection in Afar Pastoralists, Ethiopia, using QuantiFERON-TB Gold In-Tube and tuberculin skin test. BMC Infect Dis.2011;11:89.

23. Pollock N, Mc Adam A, Pai M. Interferon gamma-realease assays for diagnosis of latent tuberculosis in healthcare workers in low-incidence settings: pros and cons. Clin Chem.2014;60(5):714-8.

24. Rangaka M, Wilkinson K, Glynn J. Predictive value of interferon-gamma realease assays for incident active tuberculosis: systematic rewiew and meta-analysis. Lancet Infect Dis.2012;12:45-55.

25. Diel R, Loddenkemper R, Nienhaus A. Evidence-based comparison of commercial interferon gamma release assay for detecting active TB: a meta-analysis. Chest. 2010;137(4):952-68.

26. Machingaidze $S$, Verver $S$, Mulenga $H$. Predictive value of recent QuantiFERON conversion for tuberculosis diseases in adolescents. Am J Respir Crit Care Med. 2012;186(10):1051-6.

27. Lalvani A, Pareek MA. A 100 year update on diagnosis of tuberculosis infection. Br Med Bull. 2010;93(1):69-84.

28. Bakir M, Dosanjh DPS, Deeks JJ, Soysal A, Millington KA, Efe S, et al. Use of $T$ cell-based diagnosis of tuberculosis infection to optimize interpretation of tuberculin skin testing for child tuberculosis contacts. Clin Infect Dis. 2009;48(3):302-12.

29. Gandhi NR, Weissman D, Moodley P, Ramathai M, Elson I, Kreiswirth BN, et al. Nosocomial transmission of extensively drug-resistant tuberculosis in a rural hospital in South Africa. J Infect Dis. 2013;207(1):9-17

30. Bantubani N, Kabera G, Connolly C, Rustomjee R, Reddy T, Cohen T, et al. High rate of potentially infectious tuberculosis and multidrugresistant tuberculosis (MDR-TB) among hospital inpatients in KwaZulu Natal, South Africa indicate risk of nosocomial transmission. PIOS ONE. 2014;9(3):e90868.

31. Shenoi SV, Escombe AR, Friedland G. Transmission of drug-susceptible and drug-resistant tuberculosis and the critical importance of airborne infection control in the era of HIV infection and highly active antiretroviral therapy roolouts. Clin Infect Dis. 2010;50(Suppl.3):231-7.
15. Poddubnaya LI, Shilova EP, Stepchenko IM. Epidemiologicheskie faktory i immunnye proby $v$ formirovanii grupp riska po zabolevaniyu tuberkulyozom [Epidemiological factors and immune tests in the formation of risk groups for the disease of tuberculosis]. Tuberkulyoz. 2015;5:153-4.

16. Vozyakova TR, Masterova AV, Elenkina ZhV, Kudlay DA. Kompleksnaya otsenka diagnosticheskikh metodov vyyavleniya tuberkulyoznoy infektsii u detey i podrostkov v Chuvashskoy Respublike [Comprehensive assessment of diagnostic methods for detecting tuberculosis infection in children and adolescents in the Chuvash Republic]. Rossiyskiy vestnik perinatologii $i$ pediatrii. 2017;62(4):105-12.

17. Aksyonova VA, Baryshnikova LA, Klevno NI. Novye vozmozhnosti skrininga i diagnostiki razlichnykh proyavleniy tuberkulyoznoy infektsii u detey i podrostkov v Rossii. V: Paltsev VA. (red) Kozhnaya proba s preparatom "Diaskintest» - novye vozmozhnosti identifikatsii tuberkulyoznoy infektsii. Izd. 2-e. [New possibilities of screening and diagnosing various manifestations of tuberculosis infection in children and adolescents in Russia. In: Paltsev VA (ed.) Skin test with "Diaskintest» - a new possibilities of tuberculosis infection identification. 2nd ed.]. Moscow, RF: ;2011. p. 134-52.

18. Ovsyankina ES, Gubkina MF, Panova LV, Yukhimenko NV. K voprosu o vliyanii metoda skrininga tuberkulyoznoy infektsii u detey i podrostkov na formirovanie grupp riska i diagnostiku zabolevaniya [To the question of the influence of screening methods of tuberculosis infection in children and adolescents on the formation of risk groups and the diagnosis of the disease]. Pediatricheskaya farmakologiya. 2016;13(6):617.

19. Slogotskaya L, Bogorodskaya EM, Senchikhina OYu, Nikitina GV, Kudlay DA. Formirovanie grupp riska zabolevaniya tuberkulyozom pri razlichnykh immunologicheskikh metodakh obsledovaniya detskogo naseleniya [Formation of groups at risk of tuberculosis in various immunological methods of examination of the child population]. Rossiyskiy pediatricheskiy zhurnal. 2017;20(4):204-13.

20. Poddubnaya LV, Shilova EP, Stepchenko IM, Kononenko VG. Epidemiologicheskie faktory $\mathrm{i}$ immunologicheskie proby $\mathrm{v}$ formirovanii grupp riska po zabolevaniyu tuberkulyozom [Epidemiological factors and immunological tests in the formation of risk groups for the disease of tuberculosis]. Tuberkulyoz i bolezni lyogkikh. 2015;5:153-4.

21. Aggerbeck $H$, Giemza $R$, Joshi P. Randomised Clinical trial investigating the specificity of a Novel skin test (C-TB) for diagnosis of $\mathrm{M}$. Tuberculosis infection. PloS ONE. 2013;8(5):e64215.

22. Legesse M, Ameni G, Mamo G. Community-based cross-sectional survey of latent tuberculosis infection in Afar Pastoralists, Ethiopia, using QuantiFERON-TB Gold In-Tube and tuberculin skin test. BMC Infect Dis.2011;11:89.

23. Pollock N, Mc Adam A, Pai M. Interferon gamma-realease assays for diagnosis of latent tuberculosis in healthcare workers in low-incidence settings: pros and cons. Clin Chem.2014;60(5):714-8.

24. Rangaka M, Wilkinson K, Glynn J. Predictive value of interferon-gamma realease assays for incident active tuberculosis: systematic rewiew and metaanalysis. Lancet Infect Dis.2012;12:45-55.

25. Diel $R$, Loddenkemper $R$, Nienhaus $A$. Evidence-based comparison of commercial interferon gamma release assay for detecting active TB: a metaanalysis. Chest. 2010;137(4):952-68.

26. Machingaidze S, Verver S, Mulenga H. Predictive value of recent QuantiFERON conversion for tuberculosis diseases in adolescents. Am J Respir Crit Care Med. 2012;186(10):1051-6.

27. Lalvani A, Pareek MA. A 100 year update on diagnosis of tuberculosis infection. Br Med Bull. 2010;93(1):69-84.

28. Bakir M, Dosanjh DPS, Deeks JJ, Soysal A, Millington KA, Efe S, et al. Use of $T$ cell-based diagnosis of tuberculosis infection to optimize interpretation of tuberculin skin testing for child tuberculosis contacts. Clin Infect Dis. 2009;48(3):302-12.

29. Gandhi NR, Weissman D, Moodley P, Ramathai M, Elson I, Kreiswirth BN, et al. Nosocomial transmission of extensively drug-resistant tuberculosis in a rural hospital in South Africa. J Infect Dis. 2013;207(1):9-17.

30. Bantubani N, Kabera G, Connolly C, Rustomjee R, Reddy T, Cohen T, et al. High rate of potentially infectious tuberculosis and multidrugresistant tuberculosis (MDR-TB) among hospital inpatients in KwaZulu Natal, South Africa indicate risk of nosocomial transmission. PlOS ONE. 2014;9(3):e90868.

31. Shenoi SV, Escombe AR, Friedland G. Transmission of drug-susceptible and drug-resistant tuberculosis and the critical importance of airborne infection control in the era of HIV infection and highly active antiretroviral therapy roolouts. Clin Infect Dis. 2010;50(Suppl.3):231-7. 
32. Стародубов ВИ, Щепин ОП. (ред.) Общественное здоровье и здравоохранение. Национальное руководство. Москва, РФ: ГЭОТАР-Медиа; 2014. 624 c.

33. Перельман МИ, Богадельникова ИВ. Фтизиатрия. Москва, РФ: ГЭОТАР-Медиа; 2010. 445 с

34. Шувалова ЕП. Инфекционные болезни. Москва, РФ: СпецЛит; 2014. 725 c.

35. Дьячкова СЯ, Андреева ВВ, Киньшина ММ, Кораблёва ТП. (ред.) Методические рекомендации для специалистов, участвующих в орга низации здоровьесбережения в образовательных учреждениях и в скрининговых осмотрах дошкольников, учащихся и студентов. Воронеж, РФ: Воронежский государственный университет; 2011. 326 с.

36. Покровский ВИ, Акимкин ВГ, Брико НИ, Брусина НИ, Зуева ЛП, Ковалишена ОВ, и др. Национальная концепция профилактики инфекций, связанных с оказанием медицинской помощи, и информационный материал по её положениям. Нижний Новгород, РФ: Ремедиум Приволжье; 2012. 84 с.

37. Кузин ВВ, Шматкова ЭБ, Грищенко НС, Рудницкая ТИ, Фурсов МВ Потапов ВД. Экспериментальное сравнение аэрозольного метода при дезинфекции воздуха и поверхностей, контаминированных М. tuberculosis. Туберкулёз и болезни лёгких. 2018;96(1):35-40.
32. Starodubov VI, Shchepin OP. (red.) Obshchestvennoe zdorov'ye i zdravookhranenie [Public health and health care]. Moscow, RF: GEOTARMedia; 2014. 624 p.

33. Perelman MI, Bogadelnikova IV. Ftiziatriya [Phthisiology]. Moscow, RF GEOTAR-Media; 2010. 445 p.

34. Shuvalova EP. Infektsionnye bolezni [Infectious diseases]. Moscow, RF SpetsLit; 2014. $725 \mathrm{p}$.

35. Dyachkova SYa, Andreeva VV, Kinshina MM, Korablyova TP. (red.) Metodicheskie rekomendatsii dlya spetsialistov, uchastvuyushchikh $v$ organizatsii zdorov'esberezheniya $v$ obrazovatel'nykh uchrezhdeniyakh i v skriningovykh osmotrakh doshkol'nikov, uchashchikhsya i studentov [Guidelines for professionals involved in the organization of health preservation in educational institutions and screening examinations of preschoolers, pupils and students]. Voronezh, RF: Voronezhskiy gosudarstvennyy universitet; 2011. $326 \mathrm{p}$.

36. Pokrovskiy VI, Akimkin VG, Briko NI, Brusina NI, Zueva LP, Kovalishena OV, i dr. Natsional'naya kontseptsiya profilaktiki infektsiy, svyazannykh s okazaniem meditsinskoy pomoshchi, $i$ informatsionnyy material po eyo polozheniyam [The national concept of prevention of infections associated with the provision of medical care, and information material on its provisions]. Nizhniy Novgorod, RF: Remedium Privolzh'e; 2012. 84 p.

37. Kuzin VV, Shmatkova EB, Grishchenko NS, Rudnitskaya TI, Fursov MV Potapov VD. Eksperimental'noe sravnenie aerozol'nogo metoda pri dezinfektsii vozdukha i poverkhnostey, kontaminirovannykh M. tuberculosis [Experimental comparison of the aerosol method for disinfecting air and surfaces contaminated with M. tuberculosis]. Tuberkulyoz i bolezni lyogkikh. 2018;96(1):35-40.

\section{(1) СВЕДЕНИЯ ОБ АВТОРАХ}

Бобоходжаев Октам Икрамович, доктор медицинских наук, профессор кафедры фтизиопульмонологии, Таджикский государственный медицинский университет им. Абуали ибни Сино

ORCID ID 0000-0002-8619-3426

Авгонов Зиёвудин Тулфорович, соискатель Научно-исследовательского института профилактической медицины Таджикистана ORCID ID 0000-0002-6786-7966

Сатторов Сафар Сайдамирович, соискатель Научно-исследовательского института профилактической медицины Таджикистана ORCID ID 0000-0001-9620-9551

Информация об источнике поддержки в виде грантов, оборудования, лекарственных препаратов

Работа выполнялась в соответствии с планом НИР НИИ профилактической медицины Таджикистана (№ госрегистрации 0117ТЈ00805). Финансовой поддержки со стороны компаний-производителей лекарственных препаратов и медицинского оборудования авторы не получали.

Конфликт интересов: отсутствует.

\section{АДРЕС ДЛЯ КОРРЕСПОНДЕНЦИИ:}

\section{Бобоходжаев Октам Икрамович}

доктор медицинских наук, профессор кафедры фтизиопульмонологии, Таджикский государственный медицинский университет им. Абуали ибни Сино

734003, Республика Таджикистан, г. Душанбе, пр. Рудаки, 139 Тел.: +992 (985) 868080

E-mail: bobokhojaev@mail.ru

\section{(i) AUTHOR INFORMATION}

Bobokhodzhaev Oktam Ikramovich, Doctor of Medical Sciences, Professor of the Department of Physiopulmonology, Avicenna Tajik State Medical University

ORCID ID 0000-0002-8619-3426

Avgonov Ziyovudin Tulforovich, Applicant of Scientific Research Institute of Preventive Medicine of Tajikistan ORCID ID 0000-0002-6786-7966

Sattorov Safar Saydamirovich, Applicant of Scientific Research Institute of Preventive Medicine of Tajikistan ORCID ID 0000-0001-9620-9551

Information about the source of support in the form of grants, equipment and drugs

The work was carried out according to the plan of scientific research works of Scientific Research Institute of Preventive Medicine of Tajikistan (state registration number - 0117TJ00805). The authors did not receive financial support from manufacturers of medicines and medical equipment.

Conflicts of interest: The authors have no conflicts of interest

\section{ADDRESS FOR CORRESPONDENCE:}

Bobokhodzhaev Oktam Ikramovich

Doctor of Medical Sciences, Professor of the Department of Physiopulmonology, Avicenna Tajik State Medical University

734003, Republic of Tajikistan, Dushanbe, Rudaki Ave., 139

Tel.: +992 (985) 868080

E-mail: bobokhojaev@mail.ru 


ВКЛАД АВТОРОВ
Разработка концепции и дизайна исследования: БОИ, АЗТ
Сбор материала: АЗТ, ССС
Анализ полученных данных: БОИ
Подготовка текста: ССС
Редактирование: БОИ, ССС
Общая ответственность: АЗТ

Поступила

Принята в печать
12.01.2019

26.06.2019

\section{AUTHOR CONTRIBUTIONS}

Conception and design: $\mathrm{BOI}, \mathrm{AZT}$

Data collection: AZT, SSS

Analysis and interpretation: $\mathrm{BOI}$

Writing the article: SSS

Critical revision of the article: $\mathrm{BOI}$, SSS

Overall responsibility: AZT

Submitted $\quad 12.01 .2019$

Accepted $\quad 26.06 .2019$ 